\title{
Software de interface gráfica para a carta psicrométrica
}

\author{
Rabello, G. L. ${ }^{1}$ Pellanda, G. C. ${ }^{1}$; Junior, G. L. C. ${ }^{1}$;Verdin, M. C. S. ${ }^{1}$; Rodrigues, P. F. \\ S. ${ }^{1 ;}$ Poubel, W.M ${ }^{2 *}$ \\ 1 Discente de Graduação em Engenharia Química, Universidade Federal do Espírito Santo, Alegre, ES, Brasil. \\ 2 Docente do Departamento de Engenharia Rural, Universidade Federal do Espírito Santo, Alegre, ES, Brasil. \\ *e-mail: willian.poubel@ufes.br
}

\section{Resumo}

Alguns sistemas que envolvem ar e água necessitam de variáveis, tais como temperatura do sistema, umidade específica, umidade relativa e volume do ar por massa de ar seco. Com esse intuito, surge a proposta de implementar um código com interface gráfica, no software livre Scilab, tornando possível interpor as variáveis.

\begin{abstract}
Some systems involving air and water need variables such as system temperature, specific humidity, relative humidity and air volume per mass of dry air. For this purpose, there is the proposal to implement a code with a graphical interface on the Free Software Scilab, making it possible interpose the variables.

Keywords (Palavras chaves): carta psicrométrica, Scilab.
\end{abstract}

\section{Introdução}

Uma mistura envolvendo ar e vapor de água pode ser entendida pela psicrometria, que estuda as propriedades termodinâmicas da composição com os dois elementos. Dentro desse contexto, surge a carta psicométrica que foi inicialmente desenvolvida em 1904 pelo engenheiro Willis H. Carrier (GATLEY,2004).

Dentre a importância da Carta Psicrométrica se faz um recurso no qual relaciona a variáveis temperatura, umidade, pressão e volume. A temperatura pode ser a de bulbo seco ou bulbo úmido, que são temperaturas medidas com um termômetro.

A temperatura de ponto de orvalho é a temperatura na qual o vapor d'água começa a condensar, através de um processo de resfriamento em que a pressão e a razão de mistura se mantem constantes. Outra variável que pode ser descrita é a pressão de vapor, que está relacionada com a temperatura especifica de um determinado ambiente (HIMMEMBLAU, RIGGS, 2006). A umidade relativa relaciona a pressão parcial de vapor e a pressão de saturação à uma determinada temperatura, enquanto a umidade específica é a razão entre a massa de vapor d'água e a massa de ar úmido. Vale também destacar a variável entalpia, que é a energia contida na unidade de ar úmido por unidade de massa de ar seco (MORAN Et al). A última variável a se destacar nesse artigo é o volume específico, que é o volume por unidades de ar seco (SMITH Et al, 2007).

\section{Objetivo}

O intuito desse artigo é correlacionar as variáveis da carta psicrométrica com auxílio de um recurso computacional que favoreça o contato com o usuário. Para essa finalidade utilizou-se uma interface gráfica do Scilab para a determinação dos valores necessários.

\section{Metodologia}

Inicialmente foi implementado um código computacional na linguagem necessária do Scilab, em que necessita de dois valores resultando nos demais. O programa computacional foi realizado em uma interface gráfica com os comandos disponíveis do software Scilab. 


\section{Equacionamento}

A umidade específica utiliza-se a definição (MORAN Et al):

$$
\omega=\frac{M_{v}}{M_{a}}
$$

Onde $\mathbf{w}=$ umidade específica, $\mathrm{Mv}$ = massa do vapor de água e $\mathrm{Ma}=$ massa do ar seco.

Sabendo que a equação para um gás ideal:

$$
P V=N R T
$$

$\mathrm{E} P=\mathrm{Pv}+\mathrm{Pa}$, podemos equacionar umidade especifica como descrita na equação 3 (MORAN Et al):

$$
\omega=0.622 * \frac{P v}{P-P v}
$$

Onde $\mathrm{P}=$ é a pressão, $\mathrm{Pv}=$ pressão parcial do vapor, $\mathrm{Pa}=$ pressão parcial do ar, $\mathrm{V}=$ volume, $\mathrm{R}=$ constante dos gases e $\mathrm{T}$ = temperatura.

Outra variável é a umidade relativa que é definida pela razão da fração do vapor de água no ar úmido pela fração de vapor de água no ar saturado.

Matematicamente seria denotado por:

$$
\emptyset=\frac{Y_{v}}{Y_{v, s a t}}
$$

No qual as variáveis são descritas: $\varnothing=$ umidade relativa, $Y v$ = fração de vapor de água no ar úmido, Yv,sat = fração de vapor de água no ar saturado. $\mathrm{O}$ volume específico que é representado por V/Ma pode ser analisada como volume de ar seco por massa de ar ou volume de vapor de água por massa de ar. O equacionamento dessa variável é proveniente da equação dos gases ideais. Outras variáveis presentes na carta psicrométrica são a temperatura e a entalpia do sistema.

\section{Resultados e discussão}

A página inicial da interface gráfica no Scilab apresenta uma divisão de quatro colunas, subdivididas em blocos. $\mathrm{Na}$ primeira coluna informa os nomes de cada variável disponível no programa, entalpia, temperatura de bulbo seco e úmido, umidade específica, umidade relativa, e volume / (massa de ar). Na próxima coluna apresentação a região que permite ao usuário informar os valores que já são conhecidos. Na última seção temos um bloco correspondente ao valor calculado. E na região intermediaria temos a ilustração de parte da carta psicrométrica. Essa janela inicial pode ser evidenciada pelas figuras 1, 1a e 1b.

\section{Blucher}

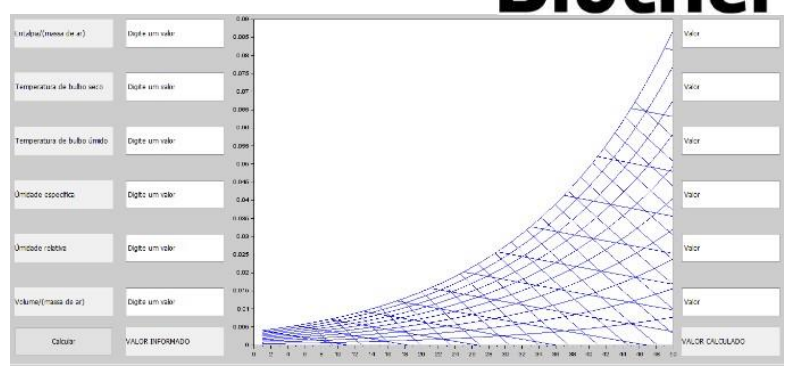

Figura 1 - Interface inicial do programa

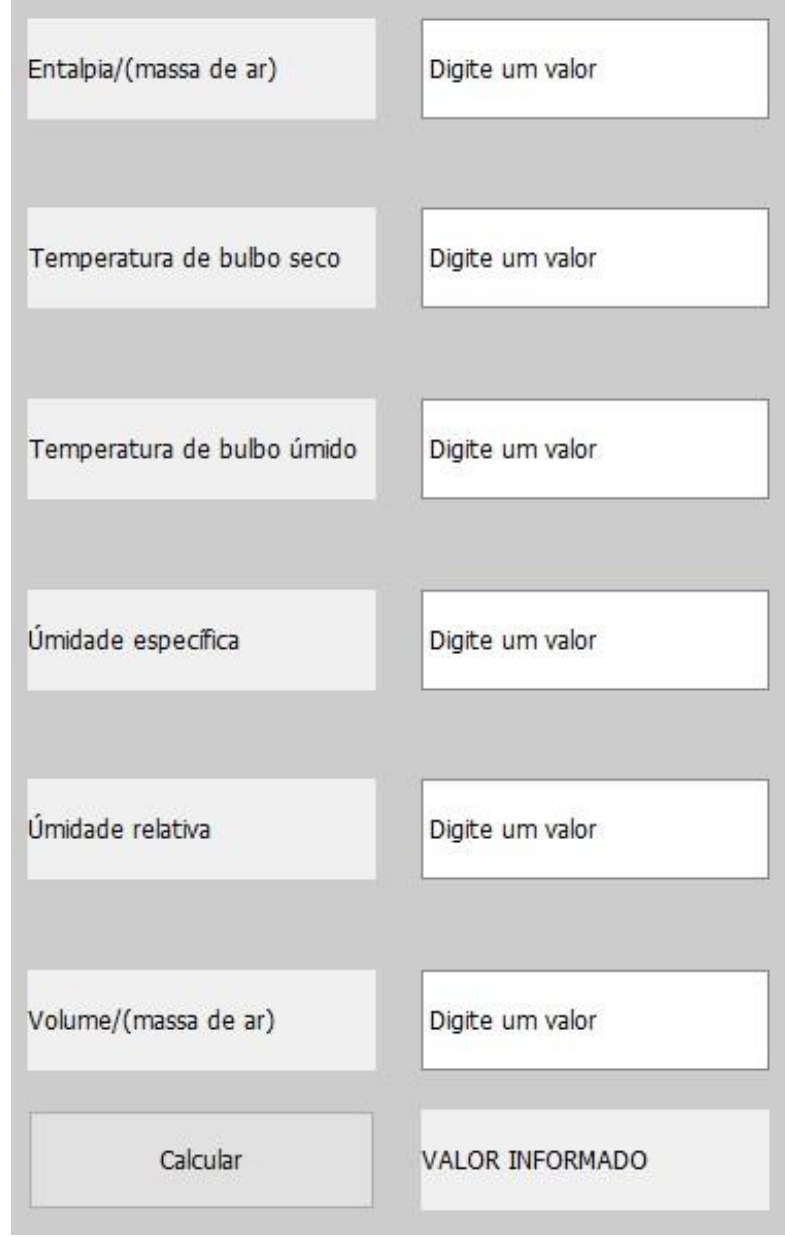

Figura 1a - primeira coluna da interface inicial

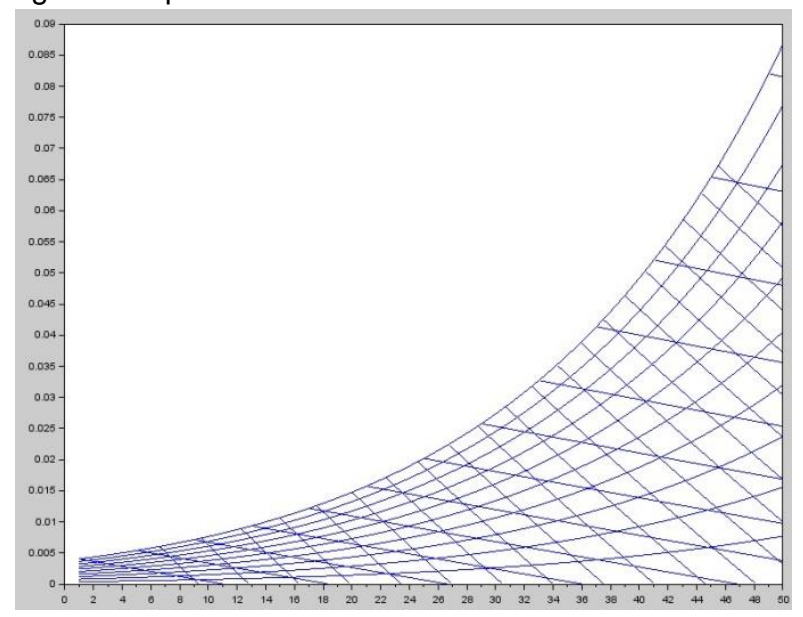

Figura 1b - Gráfico na região intermediaria 


\section{Blucher Proceedings \\ V SEMANA DE ENGENHARIA QUÍMICA UFES}

No caso a seguir assumiu-se um valor de $30^{\circ} \mathrm{C}$ e que a fração de valor de água no ar úmido corresponde a metade se comparado com o valor de vapor de água no ar saturado.

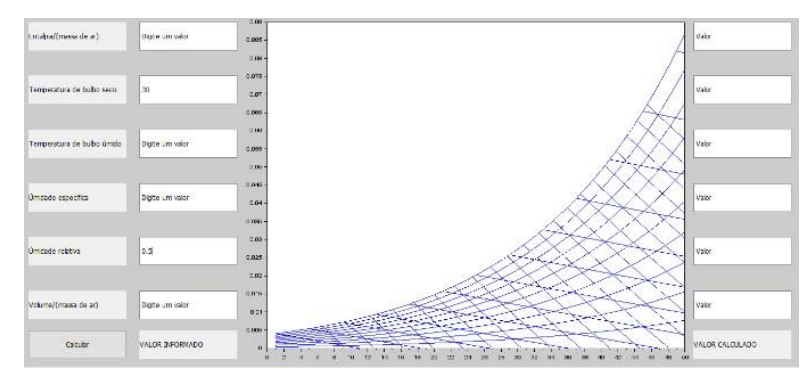

Figura 2 - Valores informados pelo usuário

Dessa forma o programa é capaz de determinar as outras variáveis não conhecidas previamente. Os resultados calculados serão disponibilizados ao usuário após a execução de um clique na caixa nomeada por "Cálculo" conforma ilustrado na imagem a seguir.

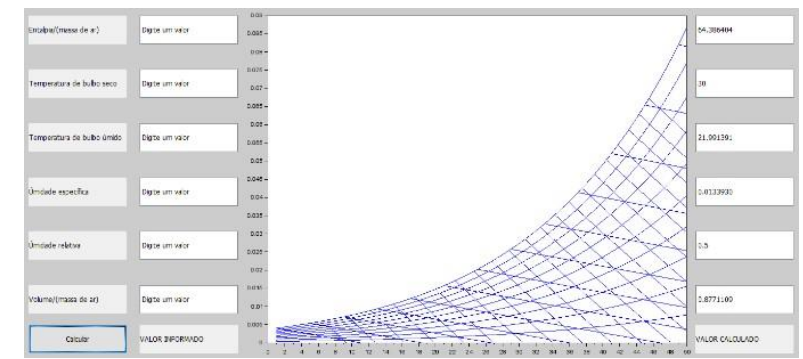

Figura 3 - Valores calculados pelo programa

Após a execução do programa verifica-se na última coluna os valores calculados de temperatura igual a $30^{\circ} \mathrm{C}$, umidade relativa de 0.5 e umidade específica de 0.01339 conforme similar ao exemplo do livro do Shapiro, o código ainda permite o conhecimento da entalpia, temperatura de bulbo úmido e volume especifico que nesse caso foram $64.38,21.99{ }^{\circ} \mathrm{C}$ e
0.877 respectivamente. Contudo, informando-se outros dois valores para esse mesmo ponto, os resultados finais não apresentaram desigualdades. Diversas combinações possíveis de duas variáveis informadas foram averiguados no código.

\section{Conclusão}

No término da implementação da interface gráfica percebe-se que se torna uma forma viável no auxílio de problemas que envolve ar úmido, pois permite a obtenção de forma satisfatória a maioria das variáveis presentes na carta psicrométrica.

\section{Referência}

MORAN, M. J.; SHAPIRO, H. N. BOETTNER, D.; BAILEY, M.B. Princípios de termodinâmica para engenharia. 7. ed.

Gatley, D. P. Psychrometric Chart Celebrates 100th Anniversary, ASHRAE Journal, v. 46. n. 11. P. 16-20, $2004 . \quad$ Disponivel em: <http://www.ashrae.org/File\%20Library/docLib/Public/A SHRAE-D-22915-20041029.pdf> Acesso em: 01 novembro de 2016.

HIMMEMBLAU, D. M.; RIGGS, J. B., (2006), Engenharia Química - Princípios e Cálculos, 7a Edição: LTC Editora: Rio de Janeiro.

SMITH, J. M.; VAN NESS, H. C.; ABBOTT, M. M.. Introdução à Termodinâmica da Engenharia Química. 7. ed. Rio de Janeiro: Ltc, 2007. 626 p. 